\title{
América Latina en la década de los 80
}

El tema escogido es el de "América Latina en la próxima Década". Creo que todos estaremos de acuerdo en que una aproximación a dicho tema pasa previa y necesariamente, por la consideración de la realidad económica internacional presente. No se trata, ni mucho menos de un análisis exhaustivo, pero sí de establecer algunas tendencias con el objeto de precisar, en la medida de lo posible, un marco de opciones viables para América Latina en la perspectiva de los años ochenta.

Existe un convencimiento generalizado de que los problemas actuales de la economía internacional no constituyen fenómenos más o menos complejos de carácter coyuntural, sino que estamos enfrentados a una crisis más profunda y delicada cuya naturaleza pareciera ser estructural.. Lo cierto y al margen de esta importante polémica, es que en el curso de la década de los años 70 el comportamiento de la economía internacional se modificó radicalmente y ése es el primer hecho que quisiera dejar establecido.

En efecto, en el período que va desde 1945 hasta 1973, la producción mundial creció al 5\% anual, el comercio al 7\%, los precios aumentaron moderadamente y los desequilibrios del sistema monetario no afectaron la expansión sostenida de las transacciones reales. En los setenta y particularmente a partir de 1974, el crecimiento de la producción y el comercio mundiales se redujo a cerca de la mitad del experimentado hasta 1973, los precios subieron a tasas cuatro o cinco veces mayores que hasta entonces y se agudizaron los desequilibrios de los pagos internacionales, provocándose con ello alteraciones sin precedentes, en la postguerra, en la paridad del dólar y de las otras monedas fuertes.

Algunos han querido ver en estos fenómenos una reafirmación, en los hechos, de la teoría de los límites del crecimiento y el supuesto agotamiento de los recursos naturales no renovables o de los efectos contaminantes del desarrollo económico. Otros, en mi opinión con 
una mayor objetividad y visión analfitica, ven en estos fenómenos la manifestación precisa de las severas tensiones, tanto económicas como políticas y sociales, a que está sujeto en el presente el orden internacional gestado a fines de la Segunda Guerra Mundial. Este es el segundo hecho que quisiera destacar.

La economía mundial, en el ámbito de los países occidentales y sin que a esta tendencia escapen los países socialistas, se caracteriza en la postguerra por una acelerada internacionalización de la producción y la circulación de mercancias y excedentes financieros. La rapidez de las innovaciones, particularmente en las industrias quimicas y metalmecánicas, así como en los sistemas de transportes y comunicaciones, alteraron drásticamente las estructuras preestablecidas de la producción y el comercio mundial.

En los años que siguieron a la Segunda Guerra Mundial, el liderazgo de la producción y el comercio mundial fue asumido por la industria manufacturera de base, al mismo tiempo que la baja elasticidad-ingreso de la demanda de bienes primarios, la sustitución de productos naturales por sintéticos y otros factores, deprimieron la importancia relativa de la producción de alimentos y materias primas dentro de la economía mundial. Si en la década de los años 30, las $2 / 3$ partes de las exportaciones mundiales estaba compuesta por productos primarios y $1 / 3$ parte por manufacturas, treinta años después la proporción prácticamente se invirtió. Así y bajo el liderazgo de las industrias más dinámicas, la producción y el comercio internacional crecieron a ritmos sin precedente histórico.

El principal resultado de este impresionante cambio cualitativo tiene que ver, a su vez, con un cambio radical en la intensidad y orientación del comercio internacional. Los principales protagonistas de este proceso de expansión e integración de la economía mundial fueron los países industriales avanzados, o sea los Estados Unidos, los países europeos integrados en la Comuniclad Económica Europea y el Japón. Así, en la cúspide del sistema económico occidental, șe sitúa igualmente el núcleo más dinámico de la economía contem. poránea. Las estadísticas, al respecto, son contundentes: si hacia la década de 1930 el intercambio entre países industrializados representaba el $40 \%$ del comercio mundial, hacia 1970 la proporción casi supera el $60 \%$. Así se consolida, en la cúspide de la economía mundial, el así llamado Sistema Trilateral. Este es el tercer hecho que quisiera destacar, especialmente porque no sólo refleja una determinada estructura del comercio internacional, sino una dinámica del proceso económico mismo que tiende a acentuarse y profundizarse por la vía 
de las inversiones y la integración de los mercados financieros entre los Estados Unidos, Europa y el Japón.

La evolución de las relaciones económicas y comerciales entre América Latina y los Estados Unidos, es un buen ejemplo de ese tipo de desarrollo que caracteriza a la expansión del comercio internacional en las últimas décadas. En el tanto Estados Unidos pasó a depender menos de América Latina, reforzando e incrementando su volumen de intercambio con el núcleo de los países altamente desarrollados, América Latina no logró diversificar en la misma intensidad sus relaciones comerciales con otras áreas $\gamma$, en lo fundamental, sigue dependiendo del comercio con los Estados Unidos. Algunas estadísticas confirman este hecho: mientras en 1950 Estados Unidos obtenía en América Latina el 35\% de sus importaciones, en 1970 lo hacía en sólo el 16\% y en 1978 obtuvo apenas el 12\%. Asimismo, en 1950 vendía en América Latina casi el $28 \%$ de sus exportaciones, el $15 \%$ en 1970 y sólo el 14,5\% en 1978. Por su parte, América Latina que obtenía la mitad de sus importaciones en Estados Unidos en 1950, bajó al $37 \%$ en 1970 y al $28 \%$ en 1977 la participación de las compras a ese país en sus importaciones totales. En cuanto a sus exportaciones, colocaba en ese mercado el $48 \%$ en 1950 , el $.4 . \%$ en 1970 y el $33 \%$ en 1977 . En razón de esta tendencia del comercio, la mayor parte de los países de América Latina mantienen una balanza comercial desfavorable con los Estados Unidos. En efecto y aún considerando las exportaciones de petróleo, desde 1971 América Latina sólo logró obtener un saldo comercial a su favor en 1977, renovándose una vez más la tendencia negativa en 1978, acumulando en el período que va desde principios de la década de los setenta, o sea de 1971 hasta 1978, un déficit con los Estados Unidos cercano a los once mil millones de dólares. Si excluimos el petróleo el déficit llega a los 22 mil setecientos millones durante ese mismo período.

Nó obstante y en lo que tiene que ver con el Sistema Trilateral, es importante señalar la disparidad de los ritmos de acumulación y crecimiento de la productividad entre los Estados Unidos, Japón y algunos países de la Comunidad Económica Europea, especialmente la República Federal Alemana. Paralelamente a la impresionante expansión del comercio mundial entre los países industrializados, se debilitó la competitividad de la economía norteamericana con respecto a estos dos últimos países. Este factor, unido a otros desequilibrios, generará un persistente y agudo déficit comercial y de balanza de pagos global de los Estados Unidos que, finalmente, provocará en 1971 la ruptura del sistema monetario mundial establecido en 
1944 con Ios acuerdos de Bretton Woods. Este hecho señala un cambio cualitativo importante en el contexto mundial. Al concluir la Segunda Guerra Mundial los Estados Unidos surgieron con una abrumadora posición hegemónica dentro del mundo desarrollado. Hacia 1950 el producto norteamericano representaba el $60 \%$ del producto de todo el mundo industrializado. La rápida reconstrucción de los países beligerantes europeos y de Japón $y$, posteriormente, su rápido desarrollo, modificaron sustancialmente las posiciones relativas de los países industrializados. En la década de 1970 la participación norteamericana en el producto del Sistema Trilateral disminuyó al $47 \%$ y tres países industrializados (Alemania Federal, Japón y Francia) representan actualmente el $80 \%$ del producto norteamericano. Esta dispersión del poder económico entre los países integrantes del Sistema Trilateral fue acompañado por una creciente competencia internacional entre sus empresas para la venta de bienes de capital y tecnología y la realización de inversiones directas en el resto del mundo. Al mismo tiempo, es importante tener presente que la expansión de los mercados financieros internacionales, como el eurodólares, multiplicó las fuentes de recursos disponibles y la competencia entre banqueros e intermediarios financieros que operan a escala intermacional. Este cambio cualitativo en la correlación de poder en la cúspicle constituye el cuarto punto que quisiera destacar.

Otro hecho fundamental de la postguerra lo constituye la expansión a escala transnacional de las grandes corporaciones industriales, comerciales y financieras. La capacidad de acumulación, dotación de tecnología y aptitud para operar a escala mundial, les permitió a estas empresas participar activa y agresivamente en la difusión de la tecnología y en la integración multinacional de la producción y los mercados, cambiando sustancialmente el cuadro de las relaciones internacionales y el patrón histórico del desarrollo económico.

A estos hechos de naturaleza económica tenemos que agregar, necesariamente, otros de carácter político, a fin de completar este cuadro sucinto del marco internacional de la postguerra. En primer lugar, la disolución del orden colonial y el surgimiento de una serie de nuevos Estados Independientes, particularmente en Africa y Asia, así como en el Caribe. En 1938, antes de la Segunda Guerra Mundial, el $80 \%$ de la superficie terrestre y el $75 \%$ de la población mundial estaba bajo el dominio de las grandes potencias occidentales. EI acelerado proceso de independencia de los años cincuenta y sesenta, desarrollará a su vez una nueva base económica para las relaciones 
internacionales. El así llamado Tercer Mundo irrumpe como un factor nuevo en el ámbito mundial.

El otro hecho político y económico de la postguerra lo constituye el desarrollo y consoliclación del campo socialista, primero en Europa y luego en otros continentes. Este año, precisamente, la organización económica y de cooperación de los países socialistas, el Consejo de Ayuda Mutua Económica (CAME), celebra su treinta aniversario con diez Estados Miembros que abarcan el $19 \%$ del territorio del mundo, el $10 \%$ de su población y un tercio de la producción industrial. A la vez, su participación en el comercio internacional es creciente, representando en 1977 alrededor del 10\% del total de las exportaciones e importaciones, lo que supera como conjunto a un mercado de la envergadura del Japón.

Desde nuestra perspectiva regional, las tendencias de la economía internacional entre $1945 \mathrm{y}$ comienzos de la década de 1970 impactaron profundamente en América Latina. Al análisis que hemos realizado con respecto a los Estados Unidos, debe agregarse como hecho global que entre fines de los cuarenta y 1970, la participación de las exportaciones latinoamericanas en las mundiales disminuyó del $11 \%$ al $5 \%$. En los últimos 25 años, a la vez, en América latina se aceleró y extendió el proceso de industrialización, orientado a abastecer el mercado interno y a satisfacer las nuevas demandas subregionales como consecuencia de los procesos de integración. En general y no obstante que los acontecimientos gestados en el plano internacional provocaron repercusiones específicas a cada país, según las condiciones particulares de cada uno de ellos, lo cierto es que el modelo tradicional de desarrollo vinculado a un esquema agroexportador, fue sustituido por un proceso de industrialización y sustitución de importaciones. De esta forma, la transformación interna y la vinculación de América Latina a las nuevas corrientes de la economía internacional, particularmente la expansión de las empresas transnacionales, generó nuevos vínculos entre las realidades internas y la economía mundial. La industrialización indudablemente provocó cambios notables en la estructura social y en la distribución del ingreso y del poder económico, al mismo tiempo que provocó un tipo de relaciones mucho más complejo con el resto del mundo y en especial con los países desarrollados. El nuevo orden de relaciones se caracteriza por su complejidad y por su vinculación a factores como la transferencia de tecnología, la coexistencia de alta productividad y densidad de capital con otros modelos tradicionales de muy bajo producto por hombre ocupado, la vinculación de los sistemas 
financieros internos con los centros internacionales y el compromiso creciente de amplios sectores sociales a los valores y pautas de desarrollo imperantes en los países industrializados. De allí la complejidad actual de la situación social latinoamericana y de las opciones básicas de desarrollo que enfrentan los países del área.

A principios de la década de 1970 y en el contexto de los factores que hemos señalado, concluýó el prolongado proceso de expansión económica de los países industrializados iniciado después de la Segunda Guerra Mundial. El aumento de los precios del petróleo en 1973 y el simultáneo incremento de las cotizaciones de los alimentos y materias primas agudizaron el proceso inflacionario $y$ provocaron un cambio drástico en las políticas económicas de los países del Sistema Trilateral. El fracaso de la llamada política de ingresos y la tentativa de frenar la inflación mediante las políticas tradicionales de restricción de la liquiclez y la demanda, desencadenaron la recesión de 1974-75. A su vez, la caída de la productividad durante esta fase recesiva y la tendencia de arrastre del fuerte crecimiento de los salarios nominales, acrecentaron el aumento de los costos unitarios del trabajo y de las presiones inflacionarias. EI receso coincidió así con nuevos aumentos en la tasa del crecimiento de los precios. Desde entonces, los países industrializados han sido incapaces de recuperar un ritmo de crecimiento económico compatible con el pleno empleo y de reducir las presiones inflacionarias a los niveles vigentes en la década de 1960. Desempleo e inflación se convierten así en dos males profundos que golpean la base misma de las economías industrializadas. De esta forma, entre las décadas de 1960 y 1970 , la tasa de crecimiento del producto declinó en estos países en un $30 \%$, el desempleo más que se duplicó y los precios se incrementaron en cuatro o cinco veces.

Todo parece indicar, sin embargo, que la crisis por la que atraviesan los países industrializados no obedece exclusivamente a factores económicos relacionados con insuficiencia transitoria de la deman$\mathrm{da}$, rigideces en la oferta superables a corto plazo, aumentos circunstanciales en los precios o problemas transitorios de ajuste en los pagos internacionales. Los problemas son más profundos y serios. Un informe reciente de la oEGD señala: "el primer desafío que enfrentan las sociedades industriales avanzadas es interno. ¿Cómo podrán esas sociedades adaptarse a las presiones engendradas por los cambios sociales, culturales e institucionales que se traducen en demandas diferentes sobre la distribución del producto social y en cuanto a la 
participación de los individuos en la producción y en las decisiones sociales? ¿Cómo superarán esas sociedades los conflictos de valor que dificultan la elaboración de las políticas gubernamentales? ¿Serán capaces esas sociedades de engendrar los nuevos valores, los nuevos comportamientos y las nuevas instituciones capaces de responder a los problemas de mañana?1. Por su parte, un informe de la Comunidad Económica Europea de 1978 establece: "Cada progreso del bienestar material y de la educación refuerza el deseo de la gente de participar en las decisiones que les conciernen. Esta exigencia es rechazada por la tendencia simultánea a la concentración y al gigantismo del poder económico y a la burocratización del poder político. En la base de estos conflictos existe una insatisfacción más profunda, de naturaleza moral, que cuestiona los resultados y la significación del desarrollo debido a sus efectos ecológicos, su costo humano, su ausencia de finalidad más allá de él mismo. De allí la desorientación de conciencias, un sentimiento de inutilidad e irracionalidad, fuente de la frustración y la violencia"2.

Todo parece indicar, por ello, que los países industrializados enfrentan hoy una aguda crisis interna y que la solución de sus problemas económicos actuales no podrá darse fuera del marco de profundos cambios políticos e institucionales. A su vez, las tensiones internas repercuten en las relaciones recíprocas al interior del Sistema Trilateral y los desequilibrios de éstas agudizan, por la misma razón, las tensiones internas, tanto en los Estados iUnidos como en la Comunidad Económica Europea y Japón, sin que se adviertan respuestas y soluciones claras de estos países frente a los graves problemas que enfrentan. El problema central de los países industrializados es, actualmente, cómo aumentar la productividad y, simultáneamente, lograr un sostenido crecimiento de la demanda, con pleno empleo y estabiliclad de precios. Se trata, en cierto sentido, de un círculo vicioso. El desempleo y la inflación desalientan la acumulación de capital y la penetración del cambio tecnológico, la división internacional del trabajo y, consecuentemente, el incremento de la productividad. A su vez, el lento crecimiento de la productividad, del ingreso real y la demanda, acrecientan las tensiones sociales y fomentan los conflictos por la distribución del ingreso. En este contexto, dos líneas de pensamiento se proyectan en el presente como dominantes. Una, de tipo defensivo, que pretende aceptar una baja de la tasa de creci-

${ }^{1}$ OCDE. Interfutures, Rapport final du Projet, París, 1978.

${ }^{2} \mathrm{CEE}$. Un projet pour l'Europe. Bruselas, 1978. 
miento a largo plazo, acomodar la reducida demanda de empleo mediante una disminución de la tasa de participación y de las horas de trabajo, compensando los desequilibrios sectoriales y regionales con medidas especiales para cada caso. Una de sus manifestaciones es el recrudecimiento del proteccionismo frente a la competencia emergente desde algunos países del Tercer Mundo y aun para las relaciones al interior del mismo Sistema Trilateral. La otra línea, caracterizada como ofensiva, propugna asumir el desafío del cambio, recuperar una fuerte tasa cle crecimiento y promover las transformaciones políticas e institucionales necesarias para liberar las fuerzas del crecimiento. Sea cual sea la orientación política definitiva, estos problemas no podrán ser resueltos descle fuera de las mismas economías de los países industrializados y en las condiciones contemporáneas, con todo realismo, es necesario tener presente que la expansión del comercio internacional y la transferencia de recursos desde los centros de poder hacia las economías de los países en desarrollo, descansa en gran medida en la solución de los problemas internos que actualmente enfrentan las economías de los países industrializados. Este es otro hecho fundamental que quisiera destacar.

La última Conferencia de las Naciones Unidas sobre Comercio y Desarrollo, la $v$ unctad, recientemente celebrada en Manila, puso de manifiesto hasta qué punto estas tensiones han permeado la estructura de las relaciones económicas mundiales y el ambiente internacional. Reseñar que la $v$ unGTAD concluyó en medio de un sentimiento generalizado de fracaso no es suficiente. Lo importante es destacar de qué forma esta Conferencia puso de manifiesto una actitud dura e inflexible en los centros de poder mundial y cómo la $\mathrm{v}$ UNGTAD diferenció posiciones y conceptos sobre la crisis económica de los años setenta. En el tanto el Grupo de los 77, influido básicamente por América Latina, planteó con absoluta claridad que la "economía mundial experimenta actualmente la crisis más grave desde el final de la Segunda Guerra Mundial y que el desasosiego que se sigue observando en el sistema económico internacional no es simplemente un fenómeno de naturaleza cíclica, sino que es sobre todo un síntoma de desajustes estructurales subyacentes y desequilibrios fundamentales", los países industrializados insistieron en caracterizar la actual situación económica mundial como coyuntural para, desde esa óptica conceptual, sugerir una serie de iniciativas que, en lo fundamental, no significaban una alseración de fondo en las relaciones económicas internacionales vigentes. EI resultado fue una UNGTAD sin acuerdos sustantivos y una nueva desilusión 
en el largo y difícil camino de la negociación Norte-Sur y la construcción de un Nuevo Orden Económico Internacional.

Un rápido balance crítico al estado actual de algunas negociaciones internacionales puede resultar ilustrativo, a los efectos de precisar las serias dificultades que enfrenta una solución negociada y mutuamente beneficiosa tanto para el norte como para el sur:

I. Las Negociaciones Comerciales Multilaterales han tenido un resultado desalentador para los países en desarrollo. En los hechos, las NCMr no sólo han negado los compromisos explícitos de la Declaración de Tokio, que dispuso un tratamiento especial y diferenciado en favor de los países en desarrollo, sino que en la práctica han fortalecido y ampliado los intercambios comerciales entre los propios países industrializados, como se desprende de cualquier análisis de las cifras del comercio mundial.

2. Igualmente desalentador es el balance final del examen y evaluación del Sistema Generalizado de Preferencias. En Manila, los países industrializados bloquearon el intento del Grupo de los 77 por dotar al sGP de un marco en el tiempo, prorrogando el sistema más allá del plazo inicial de 10 años hasta que se hayan alcanzado plenamente los objetivos expuestos en la Resolución 21 (II) y en particular hasta que los países en desarrollo alcancen, para el año 2000 , una participación del $25 \%$ en la producción industrial mundial y del $30 \%$, por lo menos, en el comercio internacional de manufacturas.

3. Tampoco se lograron progresos de importancia en los temas monetarios y financieros. El grupo de los 77 ha venido insistiendo, sin mayores progresos por la oposición del grupo de los países industrializados, en que es necesario proceder a una reforma auténtica y fundamental del Sistema Monetario Internacional, lo que presupone la adopción de una serie de decisiones en las instituciones de Bretton Woods. En Manila, asimismo, no se logró consenso sobre el establecimiento de una Comisión Internacional de la Deuda Externa.

4. Para el último cuatrimestre de 1979, en Ginebra, ha sido convocada la Conferencia Negociadora del Gódigo Internacional de Conducta para la Transferencia de Tecnología y para marzo de 1980 se ha convocado la Conferencia Internacional sobre Propiedad Industrial con el propósito de revisar la Gonvención de París. Habrá que esperar el resultado de ambas conferencias, aunque por lo que ha sucedido en Viena, en la Conferencia Mundial de Ciencia y Tecnología de 1979, es poco lo que se puede esperar en el plano de los 
resultados concretos. No muy diferente es la situación en Nueva York, en donde se ha venido negociando un Gódigo de Conducta para las Empresas Transnacionales. Los países industrializados, en esta importante negociación, se oponen a que se otorgue fuerza jurídica obligatoria al Gódigo.

5. En cuanto al Programa Integrado de Productos Básicos, es cierto que algo se ha avanzado y que en el transcurso de la $\mathrm{V}$ UNCTAD distintos países declararon al plenario de la Conferencia el monto de sus aportes voluntarios a la Segunda Ventanilla del Fondo Gomún. No obstante, aún no se ha concluido la redacción del Convenio Constitutivo del Fondo Común y, quedan por resolver problemas fundamentales entre los países industrializados y el Tercer Mundo.

Los profesionales de la negociación internacional puede que vean en este balance una simple constatación de hechos y obstáculos a superar en el futuro, en la medida que el diálogo con el norte industrializado presupone una buena dosis de "paciencia histórica". La negociación internacional ciertamente no se agotó ni llegó a su punto culminante en la $v$ UNCTAD. Hay varias instancias abiertas hacia el futuro, en la perspectiva de más largo alcance. Lo que sí alcanzó su punto máximo de saturación en Manila, es el enfoque tradicional de corte reivindicativo, expresado en una negociación fundamentada en declaraciones más o menos solemnes, que a nadie importan y que a ningún país o bloque de países preocupan. Esta quizás es una de las conclusiones más positivas de la $v$ UNGTAD. Ahora, más que nunca, se ha hecho evidente para los países del Grupo de los 77 y consecuentemente para toda América Latina, que el cambio en las relaciones económicas internacionales, en lo fundamental, dependerá más que de otros factores del esfuerzo propio, la confianza mutua y la unidad de acción por encima de las diferencias políticas o ideológicas, a fin de aumentar el poder efectivo de negociación internacional del mundo en desarrollo. No hay otra altexnativa, trátese de la negociación con el norte industrializado o con los países socialistas desarrollados. El presente obliga a una negociación concertada, fundamentada en nuevas bases y en nuevos enfoques. Las tesis meramente reivindicatorias pertenecen al pasado y a una época de alianzas y tratos especiales que nunca más regresará. Este es otro hecho que quisiera dejar claramente establecido.

Me he permitido insistir y profundizar en estos factores del entorno exterior, tanto en los que tienen que ver con algunos hechos económicos objetivos como en los resultados de la negociación interna- 
cional, por la estrecha y extrema vinculación, así como la marcada sensibilidad del ritmo de crecimiento económico de los países latinoamericanos con respecto al curso de la economía mundial.

Tal y como lo señala la Comisión Económica para América Latina (CEPAL), en su último informe presentado en $\mathrm{La} \mathrm{Paz}$, Bolivia, la región en su conjunto experimentó durante las últimas tres clécadas un proceso dinámico de desarrollo económico que puede considerarse relativamente significativo, en la medida que el producto interno bruto creció a una tasa media de 5,5\% por año. Ese ritmo es superior al de otras áreas en desarrollo, excluidos los países petroleros e incluso también mayor que el de los países industrializados tomados en su conjunto, excepción hecha del Japón en el ámbito occidental y de los países socialistas de Europa. Por otra parte y aunque es evidente que esta apreciación no tiene validez para todos los países, ni refleja la realidad de la distribución efectiva del ingreso, América Latina en su conjunto ha alcanzado un producto medio por habitante de unos 1.300 dólares a precios corrientes, lo que la ubica como región en una posición intermedia en la escala mundial, exhibiendo lo que podría llamarse un grado intermedio de semiindustrialización o semidesarrollo económico. Agrega CEPAL: "Sin embargo, es de interés hacer notar, por sus diversas connotaciones que el tamaño económico que ostenta la región, a juzgar siempre por las cifras del producto interno global, es sólo una tercera parte del que registran en conjunto los países miembros de la Comunidad Económica Europea (CEE), pero superior al que poseían esos países en 1950. Por otra parte, América Latina, que tenía en 1950 una producción neta dos veces mayor que la del Japón, tiene ahora una claramente inferior en cifras relativas ${ }^{3}$.

A partir de 1974-75, el salto inflacionario en los países industrializados, el brusco y significativo aumento en los precios del petróleo en 1973, la recesión posterior en los centros de poder económico mundial y la lenta recuperación hasta esta fecha, impactaron gravemente sobre la economía internacional y, consecuentemente, sobre la posición relativa de los países de América Latina. En los últimos años y sin que esta tendencia pareciera modificarse en la perspectiva de la próxima década, declinó aún más la tasa de expansión del comercio mundial, los precios reales de muchos productos básicos se deterioraron y, sobre todo, las presiones y las medidas proteccionistas se agudizaron en los países industrializados. Los Estados Unidos promulgaron a fines

\footnotetext{
s $V$ er cepal El desarrollo económico y social de las relaciones económicas externas de América Latina E-CEPAL-1061, 31 de enero de 1979.
} 
de 1974 la Ley de Comercio Interzacional y la Comunidad Económica Europea y Japón, por su parte, en la misma forma pusieron en práctica mediclas discriminatorias y proteccionistas. Todos estos factores afectaron las exportaciones latinoamericanas y sólo el amplio y generoso acceso al financiamiento de libre disponibilidad en los euromercados y en la banca privada internacional, permitió a varios países del área hacer frente a su agudizado desequilibrio externo, sin restricciones severas de su nivel de actividad interna. Pero este acceso al crédito internacional implicó un fuerte endeudamiento externo y del servicio de la deuda en la balanza de pagos de la mayor parte de los países de América Latina. En sentido contrario, a la vez, los nuevos precios del petróleo crearon en los países exportadores y especialmente en Venezuela, una disponibilidad de recursos que provocó cambios notables en el comportamiento de su economía. Así y sin que soluciones definitivas sean previsibles en el corto plazo, la inflación internacional y los desequilibrios en los pagos internacionales, incluyendo la inestabilidad del dolar y de las otras monedas fuertes, agudizaron las incertidumbres que enfrentan en general las economías de los países de América Latina y profundizaron aún más la brecha que nos separa de los países industrializados .

De frente a la Década cle los 80 , todo pareciera indicar que, objetivamente, hechos como la desaceleración del crecimiento del comercio mundial, el proteccionismo en los países industrializados, los desequilibrios en los pagos internacionales, las fluctuaciones en las paridades de las monedas fuertes y la inflación, probablemente continuarán imperando por algún tiempo en la economía internacional, antes de que estos factores encuentren su punto de equilibrio y la recuperación integral del sistema supere las serias dificultades del presente. No se llegará ciertamente al derrumbe del orden económico internacional como en los años 30. Los mecanismos de control del proceso económico son hoy demașiado poderosos como para permitir una violenta caída de la producción mundial y la ruptura del régimen internacional de comercio y pagos gestado en los últimos treinta años.

Es en este contexto, difícil y poco halagüeño en términos globales, en que América Latina deberá definir y precisar una estrategia de desarrollo para la Década de 1980. Se trata de una situación compleja y hasta paradojal, en que cada país tendrá que asumir la responsabilidad fundamental e intransferible de su propio destino, en el marco de sus particulares obligaciones bilaterales, subregionales y regionales, frente a un sistema crecientemente transnacionalizado e interdependiente que, en el presente, atraviesa por una de sus más 
serias crisis. Una crisis básicamente económica, pero también social y consecuentemente política.

Otro ejercicio que debemos hacer es ubicar objetiva y realistamente a América Latina en el contexto internacional del presente. Es bien conocido que al constituirse la Organización de las Naciones Unidas, a fines de la Segunda Guerra Mundial, un conjunto de menenos de cincuenta Estados suscribieron la Carta de San Francisco, de los cuales América Latina era prácticamente la mitad. Hoy el número de Estados que integran la onu casi llega a los ciento cincuenta Estados y América Latina, con la reciente incorporación del Caribe angloparlante al conjunto de naciones independientes, constituye un bloque de veintiséis Estados con un poder relativo y un margen de acción sustancialmente disminuido. Hemos pasado del papel de grandes protagonistas al de bloque integrado a Africa $y$ Asia, en el denominado Grupo de los 77. Esa es una realidad incuestionable, como también lo es que América Latina no ocupa un lugar prioritario en el interés real de los grandes centros de poder.

Hemos dejado establecido que para los Estados Unidos, Ia Comuniclad Econónica Europea y el Japón, sus relaciones recíprocas son lo principal. ¿Y después? ¿Cuál es el orden de prioridades?

La Comunidad Económica Europea, en segundo lugar, enfrenta el reto de la incorporación de Grecia, España y Portugal a su esquema integracionista; luego vienen las importantes y crecientes relaciones económicas con el bloque de países socialistas de Europa; en tercer lugar los compromisos con las ex colonias en Africa, Asia y el Caribe, a las que Francia e Inglaterra especialmente otorgan y obligan a Europa a conceder un trato preferente y diferenciado; $y$, finalmente, los países de la cuenca del Mediterráneo y particularmente las naciones árabes por razones obvias. Así, desde el punto de vista de la Comunidad Económica Europea, América Latina ocupa un quinto o sexto lugar en la lista de las prioridades reales. Este es otro hecho incuestionable.

Con los Estados Unidos la situación apenas si mejora un poco en el orden de las prioridades. Después de las relaciones con el bloque de países industrializados del Sistema Trilateral y casi paralelamente, las relaciones con los países socialistas y especialmente con la Unión Soviética, ocupan la atención prioritaria del Gobierno de Washington, no sólo en razón del equilibrio del poder mundial sino también por causa dél intercambio comercial. Ahora, además, China emerge como otro tema principal en la agenda norteamericana. Los problemas del Medio Oriente, las relaciones con Israel y los países 
árabes, o sea con las fuentes proveedoras de petróleo y energía, sin duda constituyen otro de los capítulos principales en el orden político y económico de sus prioridades. Quizás sólo después, aunque no antes de Ganadá cuya economía de hecho está integrada a la de los Estados Unidos, América Latina emerge como un tema y una prioridad norteamericana. Este es otro hecho y la cotidianidad pone de manifiesto la realidad de este nuevo alineamiento de las prioridades y los intereses mundiales.

No es muy diferente la situación en el caso de los países socialistas. Para la Unión Soviética y el bloque de naciones bajo su influencia política, militar y económica en Europa, las relaciones con los países industrializados del Sistema Trilateral son fundamentales. Luego el orden de las prioridades sigue una línea no esencialmente diferente de la occidental -excepción hecha del caso de Cuba- en lo que se refiere a los países árabes, Africa, Asia y finalmente América Latina.

Frente a esta realidad, una primera premisa es que América Latina tendrá que intensificar la concertación de posiciones unitarias, para así aumentar y potenciar su capacidad de negociación hacia afuera, a la vez que fortalecer el grado e intensidad de la cooperación intraregional. Hoy más que nunca la unidad en la diversidad es una condición previa e indispensable. No existe otra base práctica de trabajo efectivo en términos regionales y frente a la comunidad internacional.

El Sistema Económico Latinoamericano (SELA), creado en 1975 por voluntad de los 25 Estados que conforman la comunidad de países latinoamericanos y que suscribieron el Convenio de Panamá, ha demostrado que esa convergencia no sólo es necesaria sino posible y que América Latina, frente al resto del mundo, es capaz de negociar un consenso regional y alcanzar una posición común y unitaria. Ese es el camino que hemos comenzado a recorrer con la Comunidad Económica Europea. En la misma dirección se han dado algunos pasos sobre las relaciones comerciales con los Estados Unidos, especialmente referidos al análisis de los efectos negativos de álgunas çláusulas de la Ley de Comercio Exterior, así como frente al grupo de paises socialistas que integran el Gonsejo de Ayuda Mutua Económica (CANEE). No se trata de suplantar, ni mucho menos, los enfoques bilaterales, sino por el contrario de potenciar aún más esos enfoques desde una perspectiva multilateral concertada entre los países que así lo decidan libremente. Si algo tenemos claro hoy los latinoamericanos, después de dos décadas de experiencia integracionista, es que los conceptos de nación, subregión, región y comunidad internacional 
no se contraponen. De ahí que sea válido plantear y defender la tesis de que América Latina, como región, en la Década de los 80 tendrá que definir con realismo e imaginación ei alcance, los límites y las posibilidades de una estrategia de negociación concertada y de doble vía, mutuamente beneficiosa, con los países que integran la Comunidad Económica Europea, los Estados Unidos, Japón y los países socialistas desarrollados. Ese es un imperativo y una exigencia de los tiempos, como también lo es concertar las posiciones regionales que sean necesarias para actuar eficazmente en los foros de negociación multilateral.

La otra dimensión de la estrategia de América Latina en la Década de los 80 , tiene que ver con la cooperación intrarregional. Nadie pone en duda la complejidad de los procesos de integración y las dificultades que el Mercado Común Centroamericano, CArrcom en el Caribe, el Pacto Andino como resultado del Acuerdo de Cartagena y principalmente la ALAIC, han enfrentado y seguramente tendrán que seguir enfrentando. A la vez, creo que coincidiremos en que la ampliación de los mercados, la profundización de la industrialización y las economías en escala, la explotación conjunta de recursos compartidos, la complementación y la racionalidad económica, siguen siendo razones fundamentales que dan validez a la propuesta integracionista. Estos principios y otros objetivos de desarrollo, alrededor de los cuales es necesario hacer coincidir las voluntades y las decisiones políticas, son los que habría que rescatar y diferenciar de aquellos otros que sean conflictivos o que afecten los intereses nacionales, a fin de replantear y ubicar en una mejor perspectiva concreta la idea de la integración en la Década de los 80. Paralelamente y en el marco del sela, la creación y consolidación de una serie de Comités de Acción, en áreas de interés regional como la comercialización de fertilizantes, la pesca y el desarrollo de otros productos del mar y agua dulce, la vivienda de interés social, las artesanías o la creación de una Red de Información Tecnológica, cuya sede será San Pablo en Brasil, ofrecen a los países la posibilidad de un esfuerzo conjunto mutuamente beneficioso y libremente concertado

Un hecho cierto sobre el que no clebemos tener dudas es el relativo al encarecimiento de los precios del petróleo. Para la humanidad se acabó la época de las vacas gordas y nunca más habrá petróleo barato. Lo que estaría planteado en la perspectiva de la Década de los 80 , es la consideración diferenciada y preferencial, por parte de los países exportadores de petróleo, de la difícil y doblemente injusta situación de los países en desarrollo que carecen de dicho recurso 
vital. Por una parte tendremos que afrontar el alto precio del petróleo $y$, por la otra, el encarecimiento de los productos de exportación que los países industrializados trasladarán al Tercer Mundo, además de la manipulación de las grandes empresas comercializadoras. En este sentido, en la Década de los 80 se pondrá a prueba la existencia o no de una efectiva solidaridad al interior del mundo en desarrollo.

Finalmente, quisiera decir que en Ia próxima década, como objetivo fundamental del desarrollo, en América Latina y en cualquier otra región del mundo e independientemente del signo y la organización política, social y económica de cada país, la meta de todo progreso seguirá siendo el perfeccionamiento del hombre y la sociedad, en condiciones que hagan posible una efectiva justicia social y una convivencia pluralista y tolerante. Esto es particularmente importante para América Latina, en donde el desarrollo de las últimos décadas no conllevó la solución de muchos de los problemas sociales más angustiosos que confrontan los países del área y en donde amplios sectores de la población aún viven en situaciones de pobreza extrema e indigencia.

Sólo así, afrontando con responsabilidad e imaginación creadora las obligaciones que nos son propias en el ámbito de lo nacional, subregional y regional, América Latina podrá resolver sus problemas más profundos y contribuir, eficaz y positivamente, a la creación de un Nuevo Orden Económico Internacional. 